\title{
The aberrant activation of the Wnt pathway caused by $\beta$-catenin mutation and its prognostic significance in NK/T-cell lymphoma
}

\author{
B. B. QIN ${ }^{1, *}$, D. F. TANG ${ }^{2, *}$, M. L. NI ${ }^{1}$, W. GAO ${ }^{2, *}$, M. Z. ZHANG ${ }^{3, *}$ \\ ${ }^{1}$ Department of Oncology, Luoyang Central Hospital Affiliated to Zhengzhou University, Luoyang, China; ${ }^{2}$ Department of Thoracic Surgery, \\ Huadong Hospital Affiliated to Fudan University, Shanghai, China; ${ }^{3}$ Department of Oncology, The First Affiliated Hospital of Zhengzhou Uni- \\ versity, Zhengzhou, China
}

*Correspondence: zhangmingzhi_ly@163.com,gaowenchest@163.com

${ }^{*}$ Contributed equally to this work

Received September 29, 2017 / Accepted April 4, 2018

\begin{abstract}
The aberrant activation of the Wnt/ $\beta$-catenin signal has an important role in the progression of cancers. Herein, we investigated $\beta$-catenin mutation and the activation of the Wnt pathway in association with the clinical-pathological characteristics, chemo-resistance and prognosis of NK/T-cell lymphoma (NKTCL). Real-time quantitative PCR, immunocytochemistry and immunohistochemistry SP methods detected the levels of $\beta$-catenin, c-myc and cyclin D1 in human NKTCL cell lines (SNK-6 and YTS) and NKTCL tissues. Mutation analysis was detected in exon 3 of $\beta$-catenin gene; and we analyzed cell viability after histone deacetylase inhibitor (HDACi) treatment. As a result, 19 (38\%) of NK/T-cell lymphoma displayed nuclear $\beta$-catenin and $16(32 \%)$ contained mutations in exon 3; while no mutations were detected in lymphomas negative for $\beta$-catenin nuclear staining $(\mathrm{p}<0.05)$. Most mutations affecting $\beta$-catenin were adjacent to regulatory phosphorylation sites. $\beta$-catenin, $c$-myc and cyclin D1 were significantly elevated in SNK-6 and YTS cell lines compared to normal NK/T cells $(\mathrm{p}<0.05)$. Furthermore, the high expression of $\beta$-catenin, $c$-myc and cyclin D1 significantly correlated with the III/IV Ann Arbor stage. Additionally, the expression of $\beta$-catenin in the SNK-6 cell line decreased significantly after treatment with $\mathrm{HDACi}$, and Kaplan-Meier survival analysis revealed that the elevated expression of $\beta$-catenin correlated with poor prognosis in NKTCL patients $(23.66 \pm 2.77$ months vs $31.65 \pm 1.78$ months, $\mathrm{p}=0.023)$. In conclusion: mutations in exon 3 of $\beta$-catenin and the activated Wnt pathway are common in NK/T-cell lymphoma that has nuclear $\beta$-catenin, and it is closely correlated with the Ann Arbor stage and prognosis in NKTCL patients.
\end{abstract}

Key words: NK/T cell lymphoma, Wnt pathway, $\beta$-catenin mutation, chemoresistence, prognosis

Natural killer (NK)/T cell lymphoma (NKTCL) is a highly aggressive clinical-pathological subtype of non-Hodgkin lymphoma (NHL) and is most prevalent in Asian and Central and South American populations. This lymphoma has an angiocentric and angiodestructive growth pattern characteristically associated with necrosis and ulceration [1, 2]. Even with intensive therapies combining multi-agents chemotherapy and involved-field radiotherapy, the prognosis of NKTCL remains poor, with 5-year overall survival ranging from $42 \%$ to $64 \%[3,4]$. Therefore, novel alternative approaches are urgently needed.

The Wnt canonical pathway is crucial for normal cell growth and development. Substantial evidence suggests that defects in the Wnt/ $\beta$-catenin pathway are involved in the development of tumors; notably colorectal, ovarian, and breast cancer and hematological malignancies which may occur partly through the constitutive activation of the $W n t / \beta$-catenin canonical signaling pathway [5-7]. However, the precise role of the Wnt/ $\beta$-catenin pathway in NKTCL is still largely undecided.

The human $\beta$-catenin gene, CTNNB1on chromosome 3p21 is the homologue of the Drosophila Armadillo (ARM) gene. Normal cellular destabilization of $\beta$-catenin is regulated by complex interplay between GSK-3b, APC and the ubiquitin-proteosome pathway. In the absence of Wnt $/ \beta$-catenin signaling, GSK-3b phosphorylates $\beta$-catenin at the critical serine and threonine residues encoded by exon 3. The consensus sites for GSK-3b phosphorylation and ubiquitin-proteosome degradation overlap in the $\beta$-catenin NH2-terminal regulatory domain (codons 33-45). 
Activated CTNNB1 mutations have been identified in this consensus region in colon and melanoma carcinoma cell lines and epithelial tumors, including colon and endometrial cancers; thus CTNNB1 mutations are emerging as important oncogenic triggers of tumorigenesis.

Herein, we determine: a) the incidence of $\beta$-catenin nuclear localization in NKTCL; $b$ ) the incidence of $\beta$-catenin mutations in tumors with and without nuclear staining; $c$ ) analyze activation of the Wnt pathway and d) illuminate their significance with clinical characteristics, chemo-resistance and prognosis in NKTCL.

\section{Materials and methods}

Cell culture and regent. NKTCL cell lines (SNK-6 and YTS) were stored in the lymphoma diagnosis and treatment center of Henan Province in the First Affiliated Hospital. All the cells were cultured in Dulbecco's modified Eagle's medium (DMEM) supplemented with 10\% fetal bovine serum (FBS) at $37^{\circ} \mathrm{C}$ in $5 \% \mathrm{CO}_{2}$. The normal $\mathrm{CD} 56+\mathrm{NK}$ cells purified from peripheral blood used as control. SAHA was purchased from Selleck (Houston, TX, USA) and was dissolved in dimethylsulfoxide (DMSO) as $10 \mathrm{mmol} / \mathrm{L}$ stock solutions.

Patients and samples. Paraffin-embedded archived samples, including 50 NKTCL patients diagnosed according to WHO criteria between January 2011 and December 2012, and 20 reactive hyperplasia of lymph node tissue were obtained from the First Affiliated Hospital of Zhengzhou University. Clinical staging was performed according to the Improved AnnArbor installments (stage I $(n=5)$, stage II $(\mathrm{n}=29)$, stage III $(\mathrm{n}=10)$, and stage IV $(\mathrm{n}=6))$. All patients were newly diagnosed and previously untreated and they had complete clinical and pathological data. The follow-up period was the interval from the date of diagnosis to the date of death, or the last follow-up. All patients were observed until March 2014. Overall survival (OS) was the interval between the date of diagnosis and death, or the last follow up. The ethics committee of the First Affiliated Hospital of Zhengzhou University approved the protocol and we confirm that all methods were performed in accordance with the relevant guidelines and regulations. Written informed consent was obtained from all participants.

Real time fluorescence quantitative PCR (RQ-PCR). Total RNA was extracted from cell lines (SNK-6 and YTS) using TRIzol (Invitrogen) according to manufacturer's protocol. Reverse transcription reaction was then conducted by means of reverse transcription reagents (Fermentas, Guangzhou, China). Amplification reactions were performed in the ABI 7500 Real-Time quantitative PCR System using SYBR Premix Ex Taq (Thermo Fisher scientific) with cycling as follows: an initial cycle for $10 \mathrm{~min}$ at $95^{\circ} \mathrm{C}$, followed by 40 bi-phasic cycles of $15 \mathrm{sec}$ at $95^{\circ} \mathrm{C}$ and $1 \mathrm{~min}$ at $60^{\circ} \mathrm{C}$. All reactions were carried out in a $20 \mu$ reaction volume in triplicate. Gene expression was determined using the $2^{-\Delta \Delta C t}$ method with housekeeping gene $\beta$-actin as endogenous control. Specific primers for RT-PCR were obtained from Sangon (Shanghai, China), and the primer sequences were: $\beta$-catenin forward: TGGTGACAGGGAAGACATCA

Reverse: CCATAGTGAAGGCGAACTGC c-myc forward: CCTCCACTCGGAAGGACTATC

Reverse: TTCGCCTCTTGACATTCTCC

cyclin D1forward: AGGAACAGAAGTGCGAGGAG

Reverse: GGATGGAGTTGTCGGTGTAGA;

$\beta$-actin forward: GAGACCTTCAACACCCCAGC

Reverse: ATGTCACGCACGATTTCCC.

Mutation analysis of $\beta$-catenin gene. Genomic DNA samples from tumors and the corresponding normal tissues were extracted using proteinase $\mathrm{K}$ and chloroform-phenol. DNA samples were amplified for single-strand conformation polymorphism (SSCP) analysis of the $\beta$-catenin gene using PCR under the same conditions as reported previously for APC and mismatch repair genes $[8,9]$. Primers used to amplify exon 3 of the $\beta$-catenin gene were the same as those reported [10]. When abnormal bands were detected in the SSCP analysis, single-stranded DNA fragments were extracted, amplified by asymmetrical PCR and then subjected to direct sequencing by di-deoxy chain termination reaction as previously described.

Immunocytochemistry and immunohistochemical analysis. Drops of cells were plated on polylysine-coated slides and incubated at room temperature for $25 \mathrm{~min}$, then fixed with $4 \%$ polyoxymethylene. The cells were permeabilized with $0.5 \%$ Triton X-100 in PBS for 5 min, then stored at $4^{\circ} \mathrm{C}$ for further use; formalin-fixed, paraffin-embedded tissue sections of $4 \mu \mathrm{m}$ were de-paraffinized and hydrated. High-pressure antigen retrieval was performed using citrate buffer ( $\mathrm{pH} 6.0$ ), then incubated with $3 \% \mathrm{H}_{2} \mathrm{O}_{2}$ to inactivate endogenous peroxidase. Blocking was carried out with goat serum for $1 \mathrm{~h}$ to minimize non-specific binding of the primary antibody. Rabbit anti- $\beta$-catenin (1:300, LifeSpan BioSciences, Inc.), anti-c-myc (1:400, LifeSpan BioSciences, Inc.) and anti-cyclin D1 (1:300, LifeSpan BioSciences, Inc.) was then incubated overnight at $4^{\circ} \mathrm{C}$; the secondary antibody was from the SP reagent kit (Zhongshan Goldenbridge Biotechnology Company). After washing with PBS for three times, the tissue sections were treated with biotinylated anti-rabbit secondary antibody, followed by further incubation with streptavidin-horseradish peroxidase complex. Finally, diaminobenzidine tetrahydrochloride (DAB; Zhongshan Goldenbridge Biotechnology Company) was used for the signal development. The primary antibody was replaced with PBS for the negative controls simultaneously. The double-blind method was used to observe 5 horizons by two independent observers. The total immunostaining scores were calculated as the sum of percent positivity of stained tumor cells and the staining intensity. The percent of positivity was scored as follows: 0 , no staining; 1 , mild; 2 , moderate; 3 , strong; and:0, <5\%; $1,5-25 \% ; 2,26-50 \%$; $51-75 \% ; 4,>75 \%$. These scores were multiplied to give final scores of $0-12$. A staining index of $<3$ was deemed negative 
and $\geq 3$ positive ( $3-5$, weakly positive; $6-8$, moderate positive; 9-12, intense positive). The expression level was defined as following: ' - ' (score 0-3), ' + ' (score 4-6), '++' (score 7-9), and ' +++ ' (score $\geq 10$ ). Based on the expression levels, the NKTCL patients were divided into two groups: low expression $(-$ and +$)$ and high expression $(++$ and +++$)$.

Cell viability assays. Cell viability reagent functions as a cell health indicator by using the reducing power of living cells to quantitatively measure the proliferation of various human and animal cell lines. CCK- 8 reagents were added to

Table 1. $\beta$-catenin exon 3 mutations in NKTCL.

\begin{tabular}{lccccc}
\hline NKTCL & Stage & Exon & Codon & Base change & Amino acid change \\
\hline 1 & II & 3 & 45 & TCT $\rightarrow$ TGT & Ser $\rightarrow$ Cys \\
2 & II & 3 & 45 & TCT $\rightarrow$ TGT & Ser $\rightarrow$ Cys \\
3 & II & 3 & 34 & GGA $\rightarrow$ GTA & Gly $\rightarrow$ Val \\
4 & II & 3 & 11 & GAC $\rightarrow$ AAC & Asp $\rightarrow$ Asp \\
5 & II & 3 & 39 & GCC $\rightarrow$ GGC & Ala $\rightarrow$ Gly \\
6 & II & 3 & 25 & TGG $\rightarrow$ TTG & Trp $\rightarrow$ Leu \\
7 & III & 3 & 37 & TCT $\rightarrow$ TTT & Ser $\rightarrow$ Phe \\
8 & III & 3 & 37 & TCT $\rightarrow$ GCT & Ser $\rightarrow$ Ala \\
9 & III & 3 & 34 & GGA $\rightarrow$ GTA & Gly $\rightarrow$ Val \\
10 & III & 3 & 32 & GAC $\rightarrow$ TAC & Asp $\rightarrow$ Tyr \\
11 & III & 3 & 13 & GCC $\rightarrow$ ACC & Ala $\rightarrow$ Thr \\
12 & III & 3 & 41 & ACC $\rightarrow$ GCC & Thr $\rightarrow$ Ala \\
13 & III & 3 & 47 & AGT $\rightarrow$ ACT & Ser $\rightarrow$ Thr \\
14 & IV & 3 & 45 & TCT $\rightarrow$ TGT & Ser $\rightarrow$ Cys \\
15 & IV & 3 & 37 & TCT $\rightarrow$ GCT & Ser $\rightarrow$ Ala \\
16 & IV & 3 & 32 & GAC $\rightarrow$ GGC & Asp $\rightarrow$ Gly \\
\hline
\end{tabular}

Table 2. The relative expression of $\beta$-catenin, c-myc, cyclin D1mRNA in SNK-6 and YTS cells (mean \pm SD).

\begin{tabular}{lcccccc}
\hline Cell & \multicolumn{5}{c}{ Relative expression } \\
\cline { 2 - 7 } line & $\boldsymbol{\beta}$-catenin & p-value & c-myc & p-value & cyclin D1 & p-value \\
\hline NK & $1.0 \pm 0.12$ & & $2.6 \pm 0.23$ & & $0.8 \pm 0.11$ & \\
SNK-6 & $3.6 \pm 0.23$ & 0.0290 & $6.4 \pm 0.14$ & 0.0160 & $4.2 \pm 0.34$ & 0.015 \\
YTS & $2.2 \pm 0.27$ & 0.0094 & $4.0 \pm 0.17$ & 0.0358 & $3.5 \pm 0.16$ & 0.023 \\
\hline
\end{tabular}

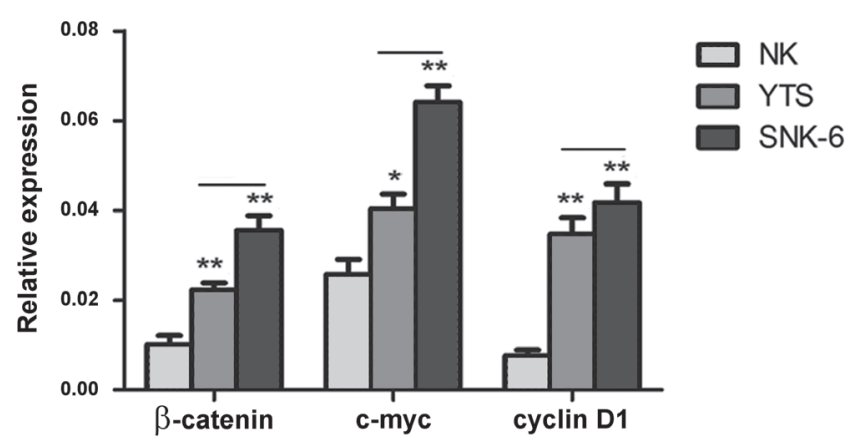

Figure 1. Up-regulated mRNA expression of $\beta$-catenin, c-myc and cyclin D1 in SNK-6 and YTS cell lines compared to normal NK cell as assessed by quantitative RQ-PCR. ${ }^{* *}$ represents $\mathrm{p}<0.01$. every subset well. The absorbance of the cells was quantified by microplate reader at $450 \mathrm{~nm}$, with reference wavelength of $630 \mathrm{~nm}$.

SAHA efficacy testing. SNK-6 cell lines were seeded in triplicate in 12 -well plates at a density of $3 \times 10^{5}$ cells per well and treated with either vehicle (DMSO) or varying concentrations $(0.03 \mathrm{mM}, 0.06 \mathrm{mM}, 0.12 \mathrm{mM}, 0.25 \mathrm{mM}, 0.5 \mathrm{mM}$, $1 \mathrm{mM}, 2 \mathrm{mM}, 4 \mathrm{mM}, 8 \mathrm{mM}, 16 \mathrm{mM}, 32 \mathrm{mM}$ ) of the HDAC inhibitor SAHA (CaymanChemical) for $48 \mathrm{~h}$. Subsequently, apoptosis was determined by flow cytometry (Accuri C6; Becton, Dickinson and Company (BD)) using the APC Annexin V Apoptosis Detection Kit with propidiumiodid (PI) (Biolegend) according to the manufacturer's instructions. Data was analyzed by Accuri C6 software (BD). The inhibitory concentration IC50 was defined as the concentration of SAHA needed to decrease cell viability by $50 \%$.

Statistical analysis. All statistical analyses were performed using the statistical software SPSS 21.0. The data was analyzed by the two-tailed Student's t-test. Pearson's $\chi^{2}$ test analyzed the relationship between the levels of $\beta$-catenin, c-myc, cyclin D1 expression and clinical-pathological features. Survival curves were calculated by the Kaplan-Meier method and compared by log-rank test. The $\mathrm{p}<0.05$ was considered statistically significant.

\section{Results}

Mutational analysis of $\boldsymbol{\beta}$-catenin. Mutations in exon 3 of $\beta$-catenin were detected in 16 of 50 tumors (32\%), and no mutations were detected in reactive hyperplasia of lymph node tissues $(\mathrm{p}<0.05$; Table 1$)$. Three mutations occurred at codons 37 and 45 which are mutational hotspots described in numerous tumor types. There were also two instances of mutations at codons 34 and 32 . Additionally, previously undescribed mutations at codons 11, 13, 25 and 39 were identified. In addition, Codon 47 is adjacent to a threonine phosphorylation site at codon 48 , and nine of the sixteen mutations occurred at or near these sites.

The expression of $\beta$-catenin, c-myc and cyclin D1 in NKTCL cell lines and tissues. We measured the expression levels of $\beta$-catenin, $c$-myc and cyclin D1 using RQ-PCR in NKTCL cell lines (SNK-6 and YTS). The mRNA expression levels were significantly elevated compared to that in normal NK cells $(\mathrm{p}<0.05$; Figure 1, Table 2$) . \beta$-catenin, $c$-myc and cyclin D1 were then examined in NKTCL tissues and NK cell lines (SNK-6 and YTS) by immunohistochemical analysis (Figures $2 \mathrm{~A}$ and $2 \mathrm{~B}$ ). Nuclear $\beta$-catenin was observed in $38 \%(19 / 50)$ of NKTCL cases, whereas no nuclear accentuation of $\beta$-catenin was found in the inflammatory lymph node tissue $(\mathrm{p}<0.05)$ (Figures $2 \mathrm{~A}-\mathrm{a}, \mathrm{b})$. Nuclear $\mathrm{c}$-myc was observed in $56 \%(28 / 50)$ of NKTCL cases and positive cases were $25 \%(5 / 20)$ in the inflammatory lymph node tissues $(\mathrm{p}<0.05)$ (Figures $2 \mathrm{a}-\mathrm{c}, \mathrm{d})$. Nuclear cyclin D1 was found in $52 \%(26 / 50)$ NKTCL cases, while positive results were $10 \%$ $(2 / 20)$ in the inflammatory lymph node tissues $(\mathrm{p}<0.05)$ 
A
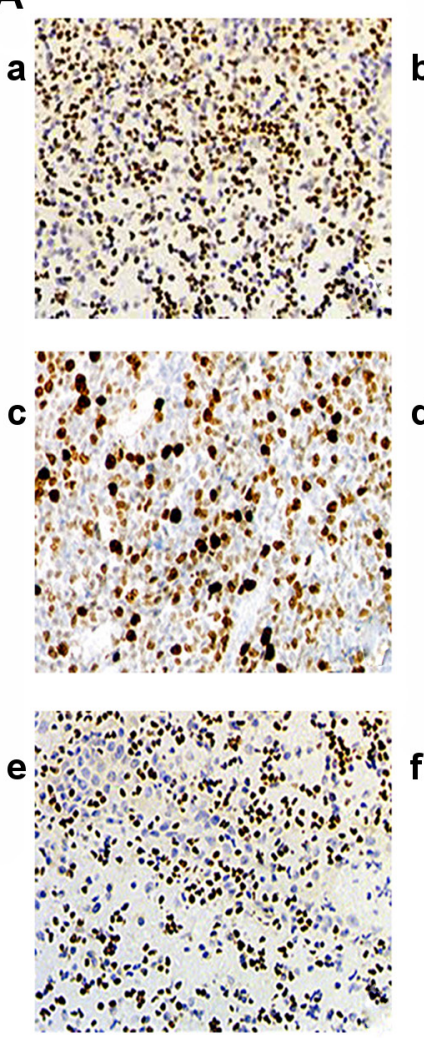
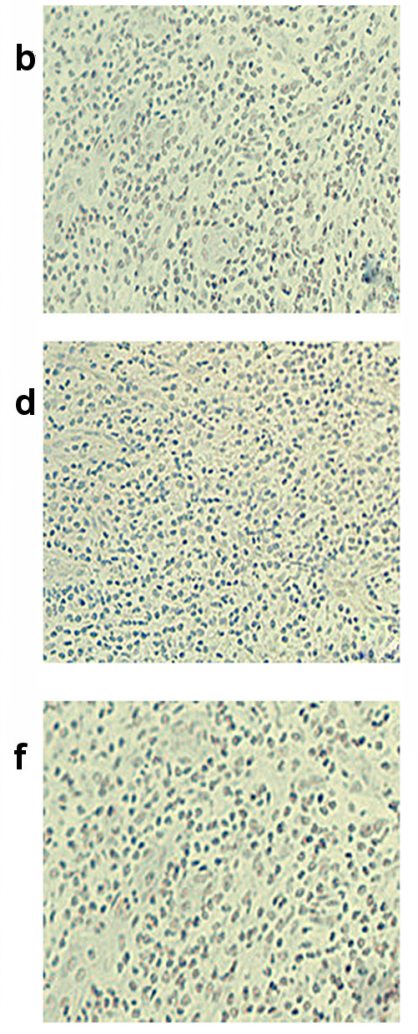

B

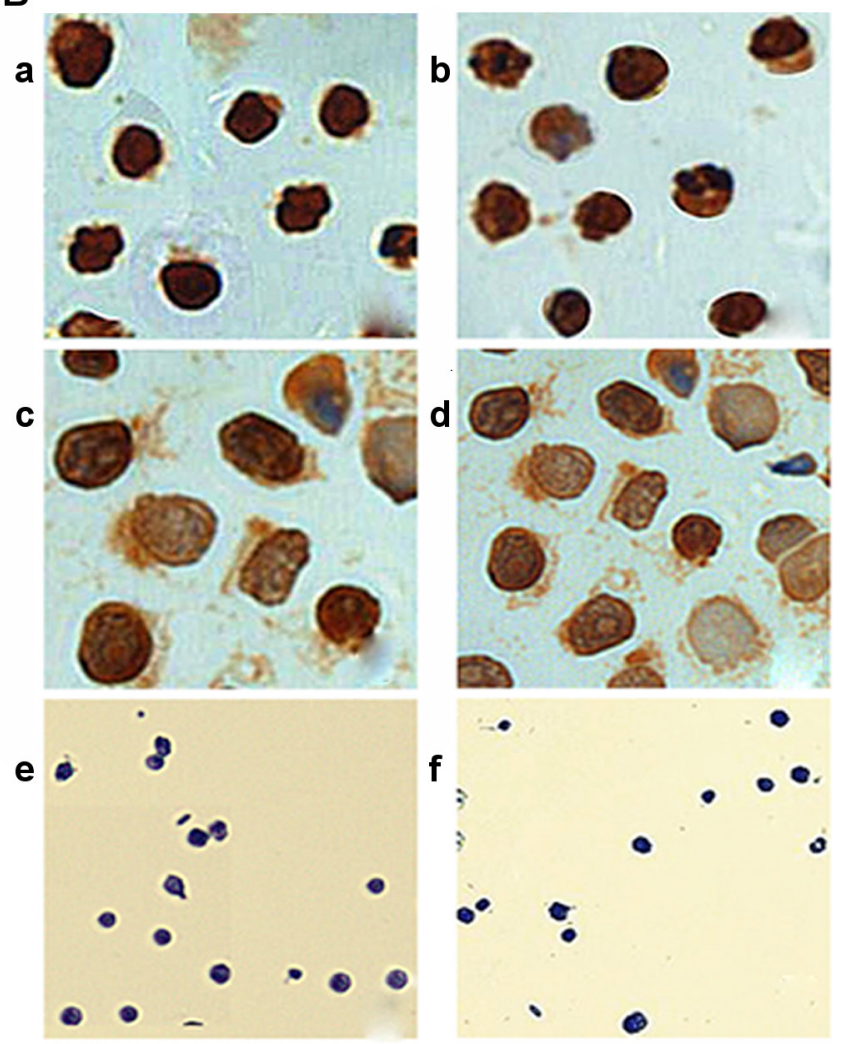

Figure 2. A) The expression of $\beta$-catenin, c-myc and cyclin D1 in SNK-6, YTS, NK/T cell lymphoma and reactive hyperplasia of lymph node by immunohistochemistry. $(a, b)$ High $\beta$-catenin expression and negative $\beta$-catenin expression in NKTCL tissues and reactive hyperplasia of lymph node $(200 \times)$. (c, d) High c-myc expression and negative c-myc expression in NKTCL tissues and reactive hyperplasia of lymph node $(200 \times)$. (e, $f)$ High cyclin D1 expression and negative cyclin D1 expression in NKTCL tissues and reactive hyperplasia of lymph node (200x). B) High $\beta$-catenin c-myc, cyclin D1 expression in YTS cell line $(a, b)$ and SNK-6 cell line $(c, d)(400 \times)$. Negative $\beta$-catenin, c-myc, cyclin D1 expression in normal NK cell $(e, f)(400 \times)$.

(Figures $2 \mathrm{~A}-\mathrm{e}, \mathrm{f}$ ). This demonstrates that the $\mathrm{Wnt} / \beta$-catenin pathway is activated in NKTCL. Table 3 shows that the Chi-square tests for $\beta$-catenin expression with $\mathrm{c}$-myc and cyclin D1 were $8.06(\mathrm{p}=0.0045)$ and $6.55(\mathrm{p}=0.0105)$, respectively, and the combined results indicate that over-expression of $\beta$-catenin had positive correlation with c-myc and cyclin D1 expression.

Relationship between the expression and the clinicopathological characteristics of NKTCL. Statistical analyses assessed the correlation between the expression of the molecular and the clinical features of NKTCL patients (Table 4). This indicated that the expression of $\beta$-catenin and cyclin D1was associated with III $(\mathrm{p}=0.009)$ and IV tumor stages $(\mathrm{p}=0.012)$, while the expression of $\mathrm{c}$-myc was associated with III+IV tumor stages $(\mathrm{p}=0.002)$ and Ki-67 levels $(\mathrm{p}=0.003)$. Other clinical characteristics, however, were not closely correlated with the expression of $\beta$-catenin and c-myc and cyclin D1; including age, gender, LDH levels, EBER levels, IPI score and effect.

SAHA reverses NKTCL chemo-resistance. We have previously shown that SNK-6 was resistant to cytarabine
Table 3. Correlation between $\beta$-catenin and c-myc, cyclin D1 expression.

\begin{tabular}{lcccccc}
\hline \multirow{2}{*}{$\beta$-catenin } & \multirow{2}{*}{ case } & \multicolumn{2}{c}{ c-myc } & & \multicolumn{2}{c}{ cyclin D1 } \\
\cline { 3 - 4 } \cline { 6 - 7 } & & positive & negative & & positive & negative \\
\hline positive & 19 & $16^{*}$ & 3 & & $15^{*}$ & 4 \\
negative & 31 & 14 & 17 & & 13 & 18 \\
total & 50 & 30 & 20 & & 28 & 22 \\
\hline
\end{tabular}

${ }^{*} \mathrm{p}<0.05$

and other chemotherapeutic agents. Herein, we investigated the effect of SAHA (HDACi) by reversing the resistance of SNK-6 and the correlation between $\beta$-catenin with drug resistance. Cell lines were treated with increasing concentrations of SAHA for $48 \mathrm{~h}$, SNK-6 cell lines with IC50 value was $4.0 \mathrm{mM}$ SAHA. We then examined the therapy efficiency of cytarabine combined with SAHA compared to cytarabine or SAHA. As a result, the expression level of $\beta$-catenin (Figure 3A) declined significantly after the combined treatment; and CCK8 results showed that SNK-6 cell line activity declined more significantly than any of the other treatments 
A

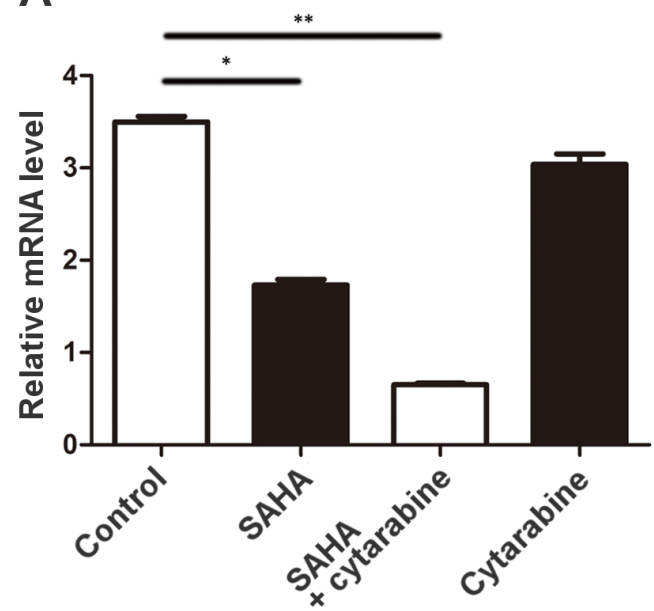

B

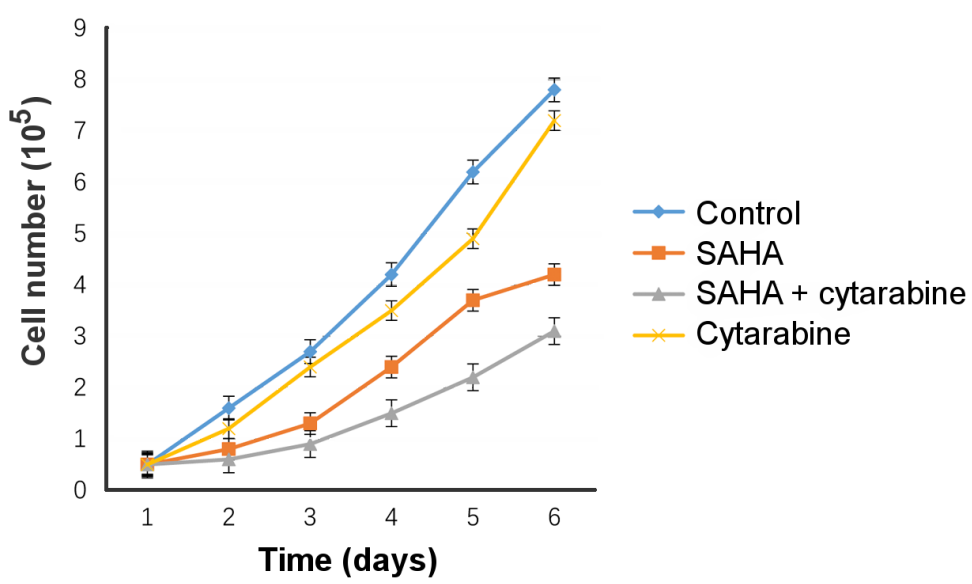

Figure 3. The expression level of $\beta$-catenin (A) and the activity of SNK- 6 cell line (B) declined significantly after SAHA treatment. ${ }^{*}$ represents p $<0.001$, ${ }^{* *}$ represents $\mathbf{p}<0.001$.

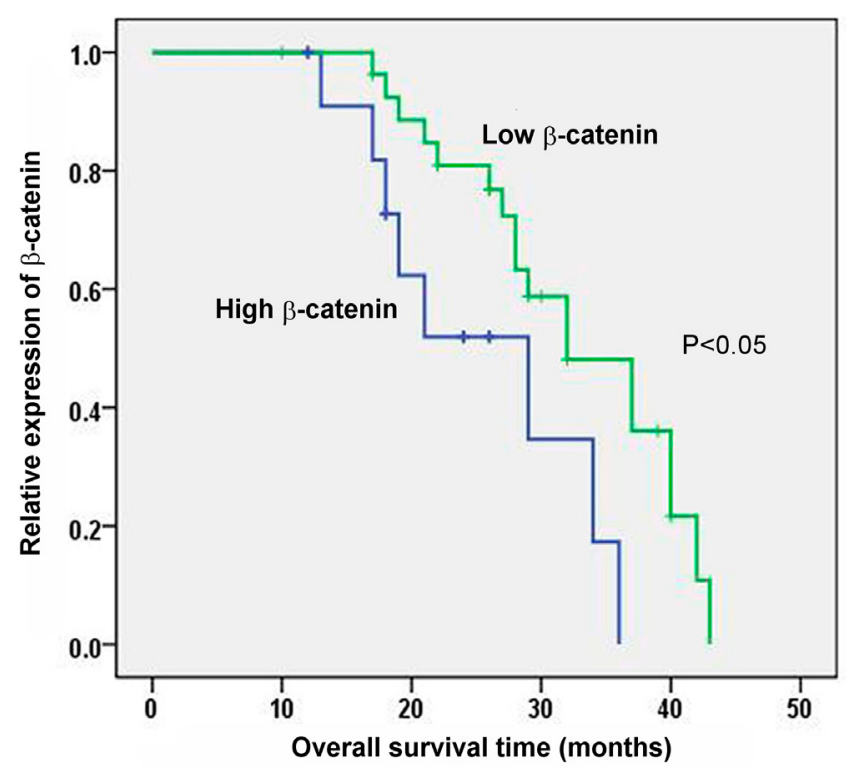

Figure 4. High $\beta$-catenin expression correlates with poor prognosis in NKTCL patients.

$(\mathrm{p}<0.001-$ Figure $3 \mathrm{~B}))$. This indicates that cell chemo-resistance was reversed by combined treatment with SAHA.

Relationship between $\boldsymbol{\beta}$-catenin expression and patient survival. We evaluated the prognostic significance of $\mathrm{c}-\mathrm{myc}$, cyclin D1, $\beta$-catenin expression in NKTCL patients and found that c-myc and cyclin D1 had no significant influence on prognosis. The Kaplan-Meier curve analysis showed that the median overall survival time was 23.66 months (95\% CI, 20.894-26.43) in the high $\beta$-catenin expression group and 31.65 months (95\% CI, 29.876-33.436) in the
Table 4. Relationship between the expression and the clinicopathological characteristics of NKTCL.

\begin{tabular}{|c|c|c|c|c|}
\hline \multirow{2}{*}{$\begin{array}{l}\text { Clinical } \\
\text { characteristics }\end{array}$} & \multirow[b]{2}{*}{ Case } & \multirow{2}{*}{$\begin{array}{c}\beta \text {-catenin } \\
\text { Positive ratio } \\
(\%)\end{array}$} & \multirow{2}{*}{$\begin{array}{c}\text { c-myc } \\
\text { Positive ratio } \\
(\%)\end{array}$} & \multirow{2}{*}{$\begin{array}{c}\text { cyclin D1 } \\
\text { Positive ratio } \\
\text { (\%) }\end{array}$} \\
\hline & & & & \\
\hline \multicolumn{5}{|l|}{ Gender } \\
\hline Men & 32 & $8(25.0)$ & $20(62.5)$ & $20(62.5)$ \\
\hline Women & 18 & $4(22.2)$ & $8(44.4)$ & $6(33.4)$ \\
\hline \multicolumn{5}{|l|}{ Age(years) } \\
\hline$\geq 60$ & 10 & $2(20.0)$ & $3(30.0)$ & $5(50.0)$ \\
\hline$<60$ & 40 & $10(25.0)$ & $25(62.5)$ & $21(52.5)$ \\
\hline \multicolumn{5}{|l|}{ Stage } \\
\hline I+II & 34 & $4(11.7)$ & $14(41.2)$ & $14(41.2)$ \\
\hline III+IV & 16 & $8(50.0)$ & $14(87.5)$ & $12(75.0)$ \\
\hline \multicolumn{5}{|l|}{ LDH } \\
\hline$<281$ & 34 & $7(20.6)$ & $18(52.9)$ & $19(55.9)$ \\
\hline$\geq 281$ & 16 & $5(31.2)$ & $10(62.5)$ & $7(43.7)$ \\
\hline \multicolumn{5}{|l|}{ EBER } \\
\hline Negative & 12 & $5(41.7)$ & $8(66.7)$ & $4(33.4)$ \\
\hline Positive & 38 & $7(18.4)$ & $20(52.6)$ & $22(57.9)$ \\
\hline \multicolumn{5}{|l|}{ IPI score } \\
\hline$\leq 2$ & 34 & $6(17.6)$ & $19(55.8)$ & $17(50.0)$ \\
\hline$>2$ & 16 & $6(37.5)$ & $9(56.3)$ & $9(56.2)$ \\
\hline \multicolumn{5}{|l|}{$\mathrm{Ki}-67$} \\
\hline$<60 \%$ & 32 & $5(15.6)$ & $13(40.6)$ & $15(46.8)$ \\
\hline$\geq 60 \%$ & 18 & $7(38.9)$ & $15(83.4)^{*}$ & $11(61.1)$ \\
\hline \multicolumn{5}{|l|}{ Effect } \\
\hline $\mathrm{PR}+\mathrm{CR}$ & 38 & $7(18.4)$ & $20(52.6)$ & $20(52.6)$ \\
\hline $\mathrm{SD}+\mathrm{PD}$ & 12 & $5(41.7)$ & $8(66.7)$ & $6(50.0)$ \\
\hline
\end{tabular}

Note: Clinicopathologic variables were compared between groups with negative expression and group with positive expression of $\beta$-catenin, c-myc, cyclin D1 in NKTCL. 
low expression group $(\mathrm{p}<0.05)$. There results indicate that high $\beta$-catenin expression significantly correlates with poor prognosis; NKTCL patients with high $\beta$-catenin expression had obviously shorter OS than those with low expression (Figure 4).

\section{Discussion}

The Wnt signaling pathway plays an essential role in embryogenesis and proliferation, survival, and differentiation of hematopoietic stem cells $[11,12]$. Herein, our data demonstrated that mutations in $\beta$-catenin exon 3 activated the Wnt pathway in NK/T-cell lymphoma which displays nuclear $\beta$-catenin. In addition, $\beta c$-catenin, $c$-myc and cyclin D1 were up-regulated in NKTCL tissues compared to inflammatory lymph node tissues. $\beta$-catenin, c-myc and cyclin D1expression strongly correlated with Ann Arbor stage; and high $\beta$-catenin expression predicated unfavorable prognosis. Therefore, aberrant activation of the Wnt pathway by $\beta$-catenin mutation can participate in NKTCL progression.

Hoshida et al. [13] reported that p53 gene mutations might have a central role in the development of adult T-cell leukemia/lymphoma in renal transplant patients, and this supports our results that post-transplantation lympho-proliferative disorder is characterized by lymphoid proliferation after organ or bone marrow transplantation.

Furthermore, we found that $\beta$-catenin mutations were in nuclear staining NKTCL tissues and there were none in plasmic staining; most mutations were adjacent to regulatory phosphorylation sites. Therefore, we speculate that $\beta$-catenin could not to be phosphorylated because of the mutations and it was unable to translocate from the nucleus, thus resulting in accumulation in the nucleus and Wnt pathway activation. Therefore, we concluded that $\beta$-catenin mutation activates the Wnt pathway and promotes c-myc and cyclin D1 expression in lymphoma; and this is supported by $\beta$-catenin mutation centralized in the high Ann Arbor stage.

The Wnt pathway is inactive in normal cells, and $\beta$-catenin is bound to GSK3 $\beta$ in the so-called "destruction complex" which promotes serine/threonine phosphorylation of $\beta$-catenin. This facilitates its proteosomal degradation. However, Wnt canonical pathway activation causes GSK3 inhibition and an increase in free pool $\beta$-catenin translocated into the nucleus, which then leads to transcription of several growth regulatory genes; including cyclin D1 and c-myc [14-16]. While those results are similar to our findings, we consider that $\beta$-catenin mutation leads to the activation of the Wnt pathway, and this promotes tumor progression.

Other involvements include; (1) c-myc is an important proto-oncogene whose over-expression can stimulate cell proliferation and block cell apoptosis [17] and (2) Cyclin D1 is a regulatory mechanism of the cell cycle which controls progress from the $G_{1}$ to the $S$ phase [18]. Therefore, the Wnt pathway may induce tumor proliferation because of its direct or indirect effects on the oncogene c-myc and cyclin D1 [19]Consequently, targeting the Wnt pathway is an innovative treatment approach $[20,21]$. Lu et al. identified the diuretic agent ethacrynic acid (EA) as a Wnt inhibitor, and cell viability assays showed that EA induced cell death in LY-8 and Raji cell lines [22]. Moreover, several small molecules such as NC043 (15-oxospiramilactone), XAV939 [23] and ICG001 have been identified in anti-cancer activity in in vivo and in vitro colon cancer, and the quercetin Wnt inhibitor has been shown to suppress growth in leukemia and lymphoma cells [24]. However, the clinical effects still require prospective multi-center and large sample trials for validation.

Herein, we have shown that $\beta$-catenin mutations occur in high Ann Arbor lymphomas resulting from Wnt pathway activation due to $\beta$-catenin mutation; and the studies have also demonstrated that $\beta$-catenin deregulation is involved in pathogenesis and chemotherapy resistance [25-28].

(1) Bellei et al. reported that the transcript levels and protein expression of $\beta$-catenin were highly elevated in the tissues of diffuse large B cell lymphoma patients, and are associated with clinical staging [29].

(2) Leshchenko et al. examined Wnt pathway transcriptional regulation and found that Wnt pathway aberrant activation has an essential role in the tumorigenesis of mantle cell lymphoma [30].

(3) Samaniego et al. found [31] that mantle cell lymphoma (MCL-ICs) is resistant to genotoxic agents vincristine, doxorubicin, and the newly approved Burton tyrosine kinase (BTK) inhibitor ibrutinib, and that MCL-ICs were particularly sensitive to Wnt pathway inhibitors. Targeting $\beta$-catenin-TCF4 interaction with Wnt inhibitors (CCT036477, iCRT14, PKF118-310) preferentially eliminated the MCL-ICs.

In conclusion, our previous study established that the SNK-6 cell line was resistant to cytarabine and other chemotherapeutic drugs, and here we found that $\beta$-catenin expression was elevated in the SNK-6 cell line. Therefore, we speculate that high $\beta$-catenin expression correlates with NKTCL resistance. The combination of $\beta$-catenin and chemotherapeutic drugs promoted translocation from cells and reduced drug toxicity, but the specific mechanism involved requires further study. Finally, we established that $\beta$-catenin expression and cell viability decreased significantly after treatment with HDACi, thus indicating that HDACi can reverse the chemo-resistance of cells with high $\beta$-catenin expression. Therefore, investigation of the role of $\beta$-catenin expression in NKTCL should aid the development of new diagnostic and therapeutic strategies.

Our planned research will next assess Wnt $/ \beta$-catenin effects on NKTCL; and especially their influence on NKTCL biological behavior and immune escape. We expect that the results will improve understanding of NKTCL molecular typing, and thus provide a solid theoretical basis for individual targeting and immunotherapy in NKTCL. 
Acknowledgments: This study was supported by funds from the National Natural Science Foundation of China (Grant No: 81301087).

\section{References}

[1] LIMA M. Aggressive mature natural killer cell neoplasms: from epidemiology to diagnosis. Orphanet J Rare Dis. 2013; 8: 95. https://doi.org/10.1186/1750-1172-8-95

[2] XU PP, WANG Y, SHEN Y, WANG L, SHEN ZX et al. Prognostic factors of Chinese patients with T/NK-cell lymphoma: a single institution study of 170 patients. Med Oncol 2012; 29: 2176-2182. https://doi.org/10.1007/s12032-011-0011-0

[3] HAMIDAH NH, SHAHROM S, SITI AISHAH MA, DAS S, GENDEH BS et al. Nasal type NK/T-cell lymphoma - diagnosis and treatment difficulties. Clin Ter 2014; 165: 139-142. https://doi.org/10.7417/CT.2014.1711

[4] SUN L, LI M, HUANG X, XU J, GAO Z et al. High-resolution genome-wide analysis identified recurrent genetic alterations in NK/T-cell lymphoma, nasal type, which are associated with disease progression. Med Oncol 2014; 31: 71. https://doi.org/10.1007/s12032-014-0071-z

[5] SEBIO A, KAHN M, LENZ HJ. The potential of targeting Wnt/beta-catenin in colon cancer. Expert Opin Ther Targets 2014; 18: 611-615. https://doi.org/10.1517/14728222.2014.9 06580

[6] WANG SH, LI N, WEI Y, LI QR, YU ZP. beta-catenin deacetylation is essential for WNT-induced proliferation of breast cancer cells. Mol Med Rep 2014; 9: 973-978. https://doi. org/10.3892/mmr.2014.1889

[7] STAAL FJ, CLEVERS HC. WNT signalling and haematopoiesis: a WNT-WNT situation. Nat Rev Immunol 2005; 5: 21-30. https://doi.org/10.1038/nri1529

[8] KONISHI M, KIKUCHI-YANOSHITA R, TANAKA K, MURAOKA M, ONDA A et al. Molecular nature of colon tumors in hereditary nonpolyposis colon cancer, familial polyposis, and sporadic colon cancer. Gastroenterology 1996; 111: 307-317.

[9] MIYAKI M, KONISHI M, KIKUCHI-YANOSHITA R, ENOMOTO M, IGARI T et al. Characteristics of somatic mutation of the adenomatous polyposis coli gene in colorectal tumors. Cancer Res 1994; 54: 3011-3020.

[10] VOELLER HJ, TRUICA CI, GELMANN EP. Beta-catenin mutations in human prostate cancer. Cancer Res 1998; 58: 2520-2523.

[11] MACDONALD BT, TAMAI K, HE X. Wnt/beta-catenin signaling: components, mechanisms, and diseases. Dev Cell 2009; 17: 9-26. https://doi.org/10.1016/j.devcel.2009.06.016

[12] KAHN M. Can we safely target the WNT pathway? Nat Rev Drug Discov 2014; 13: 513-532. https://doi.org/10.1038/ $\operatorname{nrd} 4233$

[13] HOSHIDA Y, HONGYO T, NAKATSUKA S, NISHIU M, TAKAKUWA $\mathrm{T}$ et al. Gene mutations in lymphoproliferative disorders of $\mathrm{T}$ and NK/T cell phenotypes developing in renal transplant patients. Lab Invest 2002; 82: 257-264.
[14] SHARMA A, SEN JM. Molecular basis for the tissue specificity of beta-catenin oncogenesis. Oncogene 2013; 32: 19011909. https://doi.org/10.1038/onc.2012.215

[15] GORDON MD, NUSSE R. Wnt signaling: multiple pathways, multiple receptors, and multiple transcription factors. J Biol Chem 2006; 281: 22429-22433. https://doi.org/10.1074/ jbc.R600015200

[16] KAVERI D, KASTNER P, DEMBELE D, NERLOV C, CHAN $S$ et al. beta-Catenin activation synergizes with Pten loss and Myc overexpression in Notch-independent T-ALL. Blood 2013; 122: 694-704. https://doi.org/10.1182/ blood-2012-12-471904

[17] HUANG X, SUN Q, FU H, ZHOU X, GUAN X et al. Both c-Myc and Ki-67 expression are predictive markers in patients with extranodal NK/T-cell lymphoma, nasal type: a retrospective study in China. Pathol Res Pract 2014; 210: 351-356. https://doi.org/10.1016/j.prp.2014.02.004

[18] NG SB, SELVARAJAN V, HUANG G, ZHOU J, FELDMAN AL et al. Activated oncogenic pathways and therapeutic targets in extranodal nasal-type NK/T cell lymphoma revealed by gene expression profiling. J Pathol 2011; 223: 496-510. https://doi.org/10.1002/path.2823

[19] VON SCHULZ-HAUSMANN SA, SCHMEEL LC, SCHMEEL FC, SCHMIDT-WOLF IG. Targeting the Wnt/betacatenin pathway in renal cell carcinoma. Anticancer Res 2014; 34: 4101-4108.

[20] XI Y, CHEN Y. Wnt signaling pathway: implications for therapy in lung cancer and bone metastasis. Cancer Lett 2014; 353: 8-16. https://doi.org/10.1016/j.canlet.2014.07.010

[21] KO YB, KIM BR, YOON K, CHOI EK, SEO SH et al. WIF1 can effectively co-regulate pro-apoptotic activity through the combination with DKK1. Cell Signal 2014; 26: 2562-2572. https://doi.org/10.1016/j.cellsig.2014.07.026

[22] SCHMIDT M, SIEVERS E, ENDO T, LU D, CARSON D et al. Targeting Wnt pathway in lymphoma and myeloma cells. Br J Haematol 2009; 144: 796-798. https://doi.org/10.1111/ j.1365-2141.2008.07503.x

[23] HUANG SM, MISHINA YM, LIU S, CHEUNG A, STEGMEIER F et al. Tankyrase inhibition stabilizes axin and antagonizes Wnt signalling. Nature 2009; 461: 614-620. https:// doi.org/10.1038/nature08356

[24] KAWAHARA T, KAWAGUCHI-IHARA N, OKUHASHI Y, ITOH M, NARA $\mathrm{N}$ et al. Cyclopamine and quercetin suppress the growth of leukemia and lymphoma cells. Anticancer Res 2009; 29: 4629-4632.

[25] ZHANG XY, WANG X. [Roles of signal transduction pathway in non-Hodgkin's lymphoma]. Zhongguo Shi Yan Xue Ye Xue Za Zhi 2011; 19: 532-536.

[26] SHAO N, ZOU J, LI J, CHEN F, DAI J et al. Hyper-activation of WNT/beta-catenin signaling pathway mediates anti-tumor effects of histone deacetylase inhibitors in acute T lymphoblastic leukemia. Leuk Lymphoma 2012; 53: 1769-1778. https://doi.org/10.3109/10428194.2012.663085

[27] GELEBART P, ANAND M, ARMANIOUS H, PETERS AC, DIEN BARD J et al. Constitutive activation of the Wnt canonical pathway in mantle cell lymphoma. Blood 2008; 112: 5171-5179. https://doi.org/10.1182/blood-2008-02-139212 
[28] SANCHEZ-TILLO E, FANLO L, SILES L, MONTESMORENO S, MOROS A et al. The EMT activator ZEB1 promotes tumor growth and determines differential response to chemotherapy in mantle cell lymphoma. Cell Death Differ 2014; 21: 247-257. https://doi.org/10.1038/cdd.2013.123

[29] BELLEI B, PACCHIAROTTI A, PEREZ M, FARAGGIANA T. Frequent beta-catenin overexpression without exon $3 \mathrm{mu}-$ tation in cutaneous lymphomas. Mod Pathol 2004; 17: 12751281. https://doi.org/10.1038/modpathol.3800181
[30] KUO PY, LESHCHENKO VV, FAZZARI MJ, PERUMAL D, GELLEN $\mathrm{T}$ et al. High-resolution chromatin immunoprecipitation (ChIP) sequencing reveals novel binding targets and prognostic role for SOX11 in mantle cell lymphoma. Oncogene 2015; 34: 1231-1240. https://doi.org/10.1038/ onc. 2014.44

[31] MATHUR R, SEHGAL L, BRAUN FK, BERKOVA Z, ROMAGUERRA J et al. Targeting Wnt pathway in mantle cell lymphoma-initiating cells. J Hematol Oncol 2015; 8: 63. https://doi.org/10.1186/s13045-015-0161-1 